\title{
Long-term survival of cancer patients compared to heart failure and stroke: A systematic review
}

\author{
Vasileios Askoxylakis ${ }^{1 *}$, Christian Thieke ${ }^{2}$, Sven T Pleger ${ }^{3}$, Patrick Most ${ }^{3}$, Judith Tanner ${ }^{1}$, Katja Lindel ${ }^{1}$, \\ Hugo A Katus ${ }^{3}$, Jürgen Debus ${ }^{1}$, Marc Bischof ${ }^{1}$
}

\begin{abstract}
Background: Cancer, heart failure and stroke are among the most common causes of death worldwide. Investigation of the prognostic impact of each disease is important, especially for a better understanding of competing risks. Aim of this study is to provide an overview of long term survival of cancer, heart failure and stroke patients based on the results of large population- and hospital-based studies.
\end{abstract}

Methods: Records for our study were identified by searches of Medline via Pubmed. We focused on observed and relative age- and sex-adjusted 5-year survival rates for cancer in general and for the four most common malignancies in developed countries, i.e. lung, breast, prostate and colorectal cancer, as well as for heart failure and stroke.

Results: Twenty studies were identified and included for analysis. Five-year observed survival was about $43 \%$ for all cancer entities, $40-68 \%$ for stroke and 26-52\% for heart failure. Five-year age and sex adjusted relative survival was 50-57\% for all cancer entities, about 50\% for stroke and about 62\% for heart failure. In regard to the four most common malignancies in developed countries 5 -year relative survival was $12-18 \%$ for lung cancer, $73-89 \%$ for breast cancer, 50-99\% for prostate cancer and about 43-63\% for colorectal cancer. Trend analysis revealed a survival improvement over the last decades.

Conclusions: The results indicate that long term survival and prognosis of cancer is not necessarily worse than that of heart failure and stroke. However, a comparison of the prognostic impact of the different diseases is limited, corroborating the necessity for further systematic investigation of competing risks.

\section{Background}

The facts that multiple diseases are present in many patients and that this trend is expected to increase in the future due to population ageing reveal the necessity for a better understanding of competing risks. Among the diseases with high mortality cancer, heart failure and stroke represent major global healthcare problems.

Cancer is the second most common cause of death after cardiovascular diseases. According to the World Health Organization (WHO), more than 10 million people are diagnosed with cancer yearly. The disease is responsible for 6 million deaths per year accounting for up to $12 \%$ of all cases. Fifty six percent of newly diagnosed cancer patients are $>65$ years, while about $70 \%$ of

\footnotetext{
* Correspondence: vasileios.askoxylakis@med.uni-heidelberg.de

${ }^{1}$ Department of Radiooncology and Radiation Therapy, University of Heidelberg, Im Neuenheimer Feld 400, 69120, Heidelberg, Germany
}

cancer deaths are in this age group. The median age of cancer patients at death for both sexes ranges from 71 to 77 years [1]. The four most common malignancies in developed countries are lung, breast, prostate, and colorectal cancer. These account for nearly half of all incident cases and cancer deaths of the total European cancer burden [2]. The most common entity overall and the leading cause of cancer related mortality is lung cancer. Worldwide about 1.35 million new cases and about 1.18 million deaths are estimated annually [3]. Among women the most common entity in developed countries is breast cancer. The disease is diagnosed in about 1.2 million patients and accounts for about 500,000 deaths yearly in the world [4]. Prostate cancer represents the most common cancer in men in developed countries with estimations for 2007 revealing about 782,600 new cases and 254,000 deaths [5,6]. Finally colorectal cancer is the third most common malignancy worldwide with

\section{() Biomed Central}


the WHO estimating about 945,000 new cases and 492,000 deaths annually [7].

Heart failure is a growing cause of morbidity and mortality among cardiovascular diseases, with increasing prevalence in recent years [8]. Despite significant improvements, the disease continues to represent an enormous clinical challenge. Currently, about 5 million patients are suffering in the USA from heart failure, while more than 550,000 are diagnosed yearly [9]. Incidence of the disease approaches 10 per 1000 population after age 65 and mortality was about 300,000 cases in 2006 in the USA [10]. About $80 \%$ of patients with new diagnosed heart failure are $>65$ years old and $50 \%$ are $>75$ years old. The disease is currently one of the most frequent causes of hospitalization, with the annual number in the USA estimated to be over 1 million [11].

The third leading cause of death in developed countries represents cerebrovascular disease. In 2002, stroke was the cause of 5.5 million deaths worldwide, accounting for about $10 \%$ of total deaths. The prevalence of stroke in the USA is over 700,000 cases per year [12]. About $75 \%$ of all first stroke events occur after the age of 65 years [13]. The disease is associated with high mortality in the acute phase [14]. The annual risk of death after stroke is about $10 \%[15,16]$, while the annual recurrence risk is $5 \%$ per year, similar to that seen in patients with coronary events [17].

Aim of the present article is to provide an overview of long-term survival of cancer, heart failure and stroke patients, based on the results of large locoregional and international studies. The choice of those diseases in our analysis is based on the epidemiological data concerning incidence, prevalence and mortality that underline the high impact of cancer, heart failure and stroke in public health and show that the diseases tend to affect patients of similar age.

\section{Methods}

\section{Search strategy}

We identified published studies investigating long-term survival of cancer, heart failure and stroke patients after diagnosis in different developed countries using electronic search strategies. The reference lists of identified articles were also screened and experts in the field were contacted. The comprehensive literature search was performed between February and August 2009.

Records for our study were identified by searches of MEDLINE via PubMed. Key-words used were "longterm survival", "5-year relative survival", "breast cancer", "prostate cancer", "colorectal cancer", "lung cancer", "heart failure", and "stroke". The key-words were combined using the Boolean operator "and" between survival and diagnosis type keywords.

\section{Study selection criteria}

We included large, population-based and hospital-based studies from developed countries that reported observed five-year survival and/or age- and sex adjusted five-year relative survival rates of the four most frequent cancer entities in developed countries, i.e. lung, breast, prostate and colorectal cancer, heart failure and stroke after first diagnosis. Included were studies published between 2003 and 2009. All languages and types of publications were considered eligible.

We excluded review articles and studies that investigated long-term survival restricted to a specific stage of the disease, or patients who received a specific treatment. Excluded were also studies investigating a specific patient collective, i.e. patients living under specific socioeconomic circumstances as well as studies investigating collectives of less than 200 patients. Furthermore, studies with short follow-up period (shorter than 5 years) and studies with unclear characteristics and methodology, i.e. studies which did not report the methods used for evaluation of long-term survival, such as follow-up of the collective or methodology of statistical analysis were excluded.

\section{Data extraction and assessement of methodological quality}

One reviewer (VA) screened all titles and abstracts to determinate whether the research article fulfilled the inclusion criteria. Full reports from the selected articles were retrieved by two reviewers (VA and CT) using the same criteria as for the initial selection. Data extracted included demographic characteristics, study period, identifying information and focus of the study. Primary endpoint was 5-year observed and/or 5-year age- and sex adjusted relative survival.

Methodological quality of the selected studies was assessed by two reviewers (VA and CT). Primary item used to assess study quality was the methodology applied for the determination of long-term survival. The applied methodology was deemed appropriate when follow-up was adequately completed for a time period of at least 5 years after first ever diagnosis and when survival calculation was based on period analysis methodology. Relative survival estimates were calculated as the ratio of observed to expected survival, based on calendar-year, sex and age specific life tables.

\section{Results}

\section{Identification of studies and study characteristics}

A flow diagram of the study selection process is presented in Figure 1. At the end of the selection process 20 unique citations were identified to fulfill inclusion criteria. Those citations were identified by the electronic search strategy and are published in peer-reviewed 


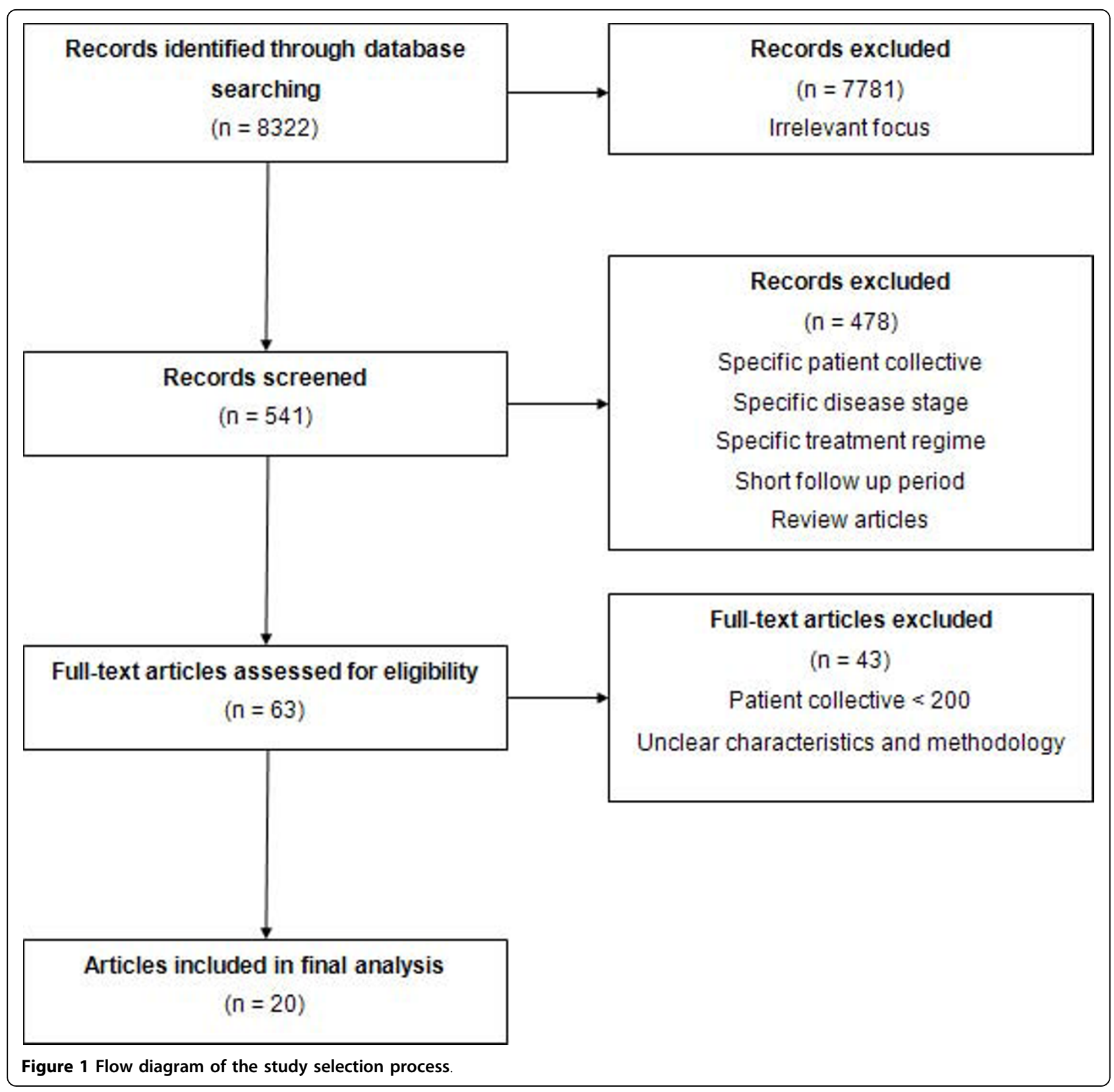

journals in the years 2003-2009. Five-year observed and/ or five-year relative survival was investigated after diagnosis or first hospitalization for each disease. An overview of the characteristics and the results of the studies included in the analysis is presented in Additional file 1. Special aspects of the included studies are presented in the next paragraphs.

\section{Long-term survival in cancer patients}

Long-term survival for cancer patients in Europe has been extensively investigated within the EUROCARE series [18-20]. Recently, the results of the EUROCARE-4 study, analyzing long-term survival of about 3 million adult cancer patients diagnosed in 1995-1999, were published [21]. Data for the population were obtained from 82 cancer registries from 23 European countries. Women had a better outcome, with 5-year observed and relative survival of 50 and $58.2 \%$, respectively (36.8 and $45.9 \%$ for men). Among all patients aged 65-74 years, the observed 5-year survival was $41.3 \%$; the value for patients $>75$ years was $24.1 \%$. Five-year relative survival was $48.1 \%$ for the age group $65-74$ years and $40.1 \%$ for patients $>75$ years.

Gondos et al analyzed data from the Saarland Cancer Registry in Germany. Five-year relative survival was $53.9 \%$ for patients aged $65-74$ years and $47.1 \%$ for 
patients $>75$ years. The same study revealed an increased 5-year relative survival over time from $42.2 \%$ in $1979-1983$ to $56.7 \%$ in $1999-2003$ [22].

\section{Lung cancer}

In the EUROCARE-4 study, 5-year observed and relative survivals were 9.5 and $11.2 \%$, respectively for patients aged $65-74$ years and 4.3 and $7.0 \%$ respectively for patients $>75$ years. A comparison with data from the EUROCARE-3 study (1990-1994) showed that survival has remained essentially unchanged [21].

In the study by Gondos et al [22] 5-year relative survival was 16.6 and $17 \%$ for the age groups $65-74$ and $>75$ years, respectively. Compared to the period 1979-1983, a modest improvement in survival was identified.

Another study from the same group compared ageadjusted 5-year relative survival for 23 common forms of cancer between patients in Germany and the USA. Comparing the results of patients with lung cancer treated in Germany and patients treated in the USA from 2000 to 2002, similar results were found [23]. Grivaux et al presented the results of an epidemiological study including all new cases of histologically confirmed lung cancer managed in general hospitals in France. The study revealed 5-year observed survival of $10.4 \%$. The median survival of the deceased patients was 7 months [24].

\section{Breast cancer}

In the EUROCARE-4 study, 5-year observed and relative survival in patients aged $65-74$ years were $72.4 \%$ and $80 \%$, respectively. Even in older patients ( $>75$ years) observed and relative 5-year survival rates were high ( $46.7 \%$ and $72 \%$, respectively). The study revealed between-country survival differences with the highest age standardized 5-year relative survival in northern Europe countries (approximately 82\%). Compared to the EUROCARE-3 study, an increasing survival trend was identified. Particularly, the mean European age- and area-standardized 5-year relative survival was 76\% for the period 1990-1994 and 79\% for the period 1995-1999 [21].

One of the first studies to provide a global comparison of cancer survival was the CONCORD study. The CONCORD study analyzed data from 101 population-based cancer registries from 31 countries. Within this study, age-standardized 5-year relative survival varied between different regions. The highest value was $83.7 \%$ for North America. Within the USA, 5-year relative survival ranged from $77.4 \%$ to $89.3 \%$, while in Europe values varied from $57.9 \%$ to $82 \%$. Among the 17 USA populations included in the study, survival was lower in blacks than in whites (70.9 vs $84.7 \%$, respectively) [25].
Within the Michigan Cancer Surveillance Program, Meliker et al showed higher survival rates for the white population [26]. The racial disparity is confirmed by the results of other studies, revealing average 5-year survival rates of $78 \%$ for black and about $90 \%$ for white women with breast cancer in the USA [27].

\section{Prostate cancer}

In the EUROCARE-4 study, 5-year observed and relative survival for patients aged $65-74$ years were $66.9 \%$ and $81.1 \%$ and for patients aged $75-84$ years $44.2 \%$ and $70.9 \%$, respectively. Five-year age-standardized relative survival varied between European countries from $48 \%$ to about $87 \%$. A trend towards improved 5-year survival was identified comparing age-standardized values of $65 \%$ in the EUROCARE-3 and $76 \%$ in the EUROCARE-4 study [21].

The CONCORD study revealed major regional differences in 5-year relative survival, especially in Europe. A race-specific analysis in the United States showed a higher survival rate for white $(92.4 \%)$ than for black patients $(85.8 \%)$ [25].

Gondos et al showed 5-year relative survival rates of $90.5 \%$ and $80.3 \%$ for patients aged $65-74$ and $>75$ years, respectively. Compared to the period 1979-1983, improved survival rates were demonstrated [22].

The same group compared the results of prostate cancer patients in Germany and the USA. Age adjusted 5year relative survival was $86.8 \%$ in Germany and $99.7 \%$ in the USA. According to the authors, this result could be explained by differences in screening intensity between the two countries [23].

Survival improvement over time was shown in a retrospective population-based study of prostate cancer cases reported to the Singapore Cancer Registry from 1968 to 2002. This study, performed by Chia et al, revealed a 7.9\% increase in 5-year relative survival for 1998-2002 compared to $1978-1982$ [28].

\section{Colorectal cancer}

Within the EUROCARE-4 study, observed and relative 5 -year survival was $46.6 \%$ and $54.3 \%$ for patients aged $65-74$ years; for older patients ( $>75$ years) the respective values were $28.5 \%$ and $47.6 \%$ [21].

In the study by Gondos et al [22] 5-year relative survival for all ages was $60 \%$ for colon cancer and $59.2 \%$ for rectal cancer, showing an increase of $16.3 \%$ and $19.5 \%$, respectively, compared to previous time periods. In the second study by this group [23], patients in USA were found to have a moderately higher relative survival in all age groups compared to patients from Germany.

Survival analysis of patients with colorectal cancer in Sweden was performed by Birgisson et al, demonstrating 
a trend to improved relative survival rates for both colon and rectal cancer [29].

The CONCORD study revealed variability in colorectal cancer survival between different countries. The same study revealed racial disparities, with black populations having lower survival rates than white populations [25].

\section{Long-term survival for heart failure}

Jhund et al investigated the long-term trends after first hospitalization for heart failure. The 5-year case-fatality rate for the entire patient population was $74 \%$. Investigation of the trend over time revealed an outcome improvement. Five-year age-adjusted case fatality decreased from $73.7 \%$ to $65.8 \%$ in men and from $69.5 \%$ to $63.6 \%$ in women between 1986 and 1999 [30].

In a study by Blackledge et al, more than $60 \%$ of the patients were older than 75 years. Five-year all cause and cardiovascular survival for all patients were $27 \%$ and $41.8 \%$, respectively. For the subpopulation of patients with heart failure as a primary diagnosis, 5-year all cause and cardiovascular survival were $24.4 \%$ and $37.9 \%$, respectively. After six years of follow up, case fatality was $75-80 \%$ with worse outcome for patients with heart failure as a primary diagnosis [31].

Mahjoub et al investigated the long-term prognosis of patients with first heart failure episode in the Somme Department (France) during 2000. Five-year observed survival rates were $19 \%$ for octogenarians and $52 \%$ for younger patients, while 5-year relative survival for octogenarians and younger patients were 40 and $62 \%$, respectively [32].

A study from the same region by Tribouilloy et al showed that 5-year survival for heart failure patients with preserved ejection fraction was equivalent to that of patients with reduced ejection fraction (43 vs. $46 \%$, respectively) [33].

Similar results for patients with preserved and reduced ejection fraction were demonstrated by Owan et al; observed 5-year survival rates were 35 and $32 \%$, respectively [34]. Thus, within two decades, improved pharmacological treatment and device technology increased survival of heart failure patients by 1 year, but $65 \%$ of all heart failure patients still died within 5 years.

\section{Long-term survival for stroke}

Bravata et al investigated long term mortality in a cohort of patients aged $>65$ years who had been discharged with a primary diagnosis of acute ischemic stroke, transient ischemic attack, or carotid stenosis from Connecticut acute care hospitals in 1995. Annual mortality rate was $20.2 \%$ for the first year and decreased to about $12 \%$ for years $2-5$. The authors showed that mortality rates depended on cerebrovascular diagnosis.
Particularly, 5-year survival rate was $61.7 \%$ for carotid stenosis, $50.4 \%$ for TIA, and $40 \%$ for acute ischemic stroke [35].

Kim et al investigated long-term survival after first stroke in a nationally representative inpatient sample in Korea. Six-year survival rate was $65 \%$. The most common causes of death were stroke and cardiovascular diseases, which were found to be responsible for $65.9 \%$ of deaths at 6-year follow-up [36].

Subanalysis of the results of a study performed by Reggiani et al revealed age and affected brain region as important prognostic factors. Five-year survival was $66.1 \%$ for patients aged $65-74$ years and $49.4 \%$ for patients aged 75-84 years [37].

Vernino et al investigated mortality in patients after first cerebral infarction between 1985 and 1989. Most frequent causes of death were cardiovascular events (22\%), respiratory infection (21\%), and initial stroke complications (14\%), while cancer accounted for $7.5 \%$ of deaths [38].

A retrospective study on patients with first ever stroke from 1996 to 1998 carried out by Cheung et al revealed 5 -year mortality rates of $56.1 \%$ for patients with intracerebral haemorrhage and $33 \%$ for patients with ischemic stroke [39].

A population-based study investigating long-term survival after first ever stroke in Australia showed a 10-year cumulative risk of death of $79 \%$. For the 10 years of follow-up, all patients had an about 3-times-greater risk of dying compared with individuals of the same age and sex in the general population [40]. A more recent study from the same group comparing 5-year survival and risk of recurrent stroke for the time periods $1989-90$ and 1995-96 revealed no statistically significant survival improvement but a trend towards a smaller cumulative risk of recurrent stroke event [41].

\section{Discussion}

Among diseases responsible for the majority of deaths worldwide, cancer, heart failure and stroke possess leading positions. Aim of this work is to provide an overview of long term survival of those diseases as described in large population- or hospital based studies from different developed countries. We chose cancer, heart failure and stroke for our analysis mainly because of their epidemiological characteristics. Incidence and mortality of the diseases demonstrate that they represent major global healthcare problems tending to affect patients of similar age. Furthermore, our clinical empiricism shows that in some cases the prognostic impact of each disease is unclear and that cancer is often considered to be the disease with the worst prognosis.

Most identified studies investigated 5-year observed survival for the disease of interest. In one of the largest 
population based studies, observed 5-year survival after diagnosis was about $43 \%$ for all cancer diseases [21]. Observed 5-year survival for heart failure varied between $26 \%$ and $52 \%$ and observed survival after a stroke event varied between $40 \%$ and $68 \%$. However, comparison of observed survival has major limitations. The observed mortality rate within the cohort of interest does not represent the mortality rate associated only with the disease of interest, but is equal to the all-cause mortality rate in the reference population plus the excess mortality rate associated with the disease. Comparisons based on observed survival rates between different studies are not reliable, since they are affected by demographic differences between the different populations. In order to eliminate such effects calculation of relative survival rates is more appropriate. Relative survival rate is defined as the ratio of the observed survival rate in a group of patients to the survival rate expected in a group of people in the general population, who are similar to the patients with respect to all of the possible factors affecting survival at the beginning of the period, except for the disease under study [42]. A relative survival rate of 1 indicates that the mortality of the study group does not differ from that expected in the general population and that the mortality attributable to the disease is zero. For the calculation of relative survival rates the expected survival is usually estimated from nationwide population life tables, stratified by age, sex and calendar time. The major advantage of relative survival is that the information on cause of death is not required [43]. The analysis of the cancer related studies identified in our investigation demonstrated 5 -year relative survival rates of $50 \%$ to $57 \%$ for all cancer entities. Differencies in 5-year relative survival was demonstrated for the different cancer entities. In particular, breast and prostate cancer showed 5-year relative survival rates of $73 \%$ to $89 \%$ and $50 \%$ to $99 \%$, respectively, while lung cancer showed considerably lower survival rates $(12 \%$ to about $18 \%)$. This result highlights the need to educate the patients and the general population that "cancer" is not one disease, but an umbrella term for a number of malignancies characterized by tissue infiltration and metastatic dissemination but manifold symptomatology, varying response to treatment strategies, and different long-term prognosis.

Five-year relative survival rates for heart failure and stroke in the studies identified in our search was about $62 \%$ and $50 \%$ respectively. A comparison to the relative survival rates of the different cancer entities indicates that cancer might not necessarily have a worse prognosis. However, this conclusion is strongly limited by various factors. The most important limiting parameter is the lack of appropriate data in regard to relative survival ratios for heart failure and stroke. Our search identified only two studies for each disease, which is not enough for safe conclusions. Furthermore, the use of relative survival rates underlies the assumption that patients are subject to two independent forces of mortality, i.e. that attributable to the disease and that in the general population. However, the disease of interest is often included in the reference population, resulting in bias of the estimation. Cancer and stroke are more closely linked to a hospital admission, while the development of screening techniques, such as PSA-screening for prostate cancer and mammography for breast cancer, has led to an earlier diagnosis of the diseases and therefore a better identification of patients and discrimination from the reference population. In case of heart failure, however, many patients are first diagnosed when symptoms become severe enough to require hospitalization. The patients that are not recognized are possibly included in the reference population, resulting in bias of the estimated relative survival rates.

Past studies have directly compared heart failure vs. cancer-related survival within the same population, showing results that are similar to the trend identified in our comparison. A study performed by Stewart et al investigated all patients with a first admission to any Scottish hospital in 1991 for heart failure and the four most common types of cancer, revealing that with the notable exception of lung cancer, heart failure was associated with a worse survival rate compared to other common cancer entities [44].

Although comparison and analysis of long term survival of different diseases is limited, it still can be an important tool for a better understanding of competing risks. The competing risks concept describes the analysis of how mortality trends of one disease might influence the mortality trends of another disease. To analyse this different models are available. The model of Chiang eliminates a specific cause in order to estimate the effect on mortality from other causes [45], while the model of Rothenberg is based on the assumption that mortality from competing causes remains constant [46]. The influence of cerebrovascular and cardiovascular disease mortality trends on cancer mortality trends has been analysed in various studies. Llorca et al analysed the interrelation between cerebrovascular disease, ischemic heart disease and cancer mortalities in Spanish women in 1981 and 1994 using both models and showed that although cerebrovascular and ischemic heart disease mortality have decreased in all age groups during the investigation period, this had not a significant impact on cancer mortality [47]. However, investigation of competing risks usually assumes independence between the different causes of death. Different causes of death are considered to be independent when they do not share common risk factors. A prominent example of a 
common risk factor between cardiovascular, cerebrovascular disease and various cancer entities is tobacco smoking. The error that is produced by the assumption of independence between those diseases is therefore influenced on the smoking prevalence of the investigated population and on the level of mortality from tobacco-related cancers [47]. The results of our systematic review cannot provide safe conlusions on competing risks, since they compare long term survival of different populations and do not provide information on risk factors that are important for analysis. Still, the competing risks problem shows the necessity for studies investigating outcome of different diseases, especially considering the fact that the number of multimorbid patients is expected to increase in the future mainly due to population ageing.

In respect to survival trends, the studies analysed here reveal results that are moderately encouraging. Comparison of long-term survival shows that the prognosis of cancer and heart failure has modestly improved over the last decades. However, a better understanding of the underlying molecular mechanisms of the diseases and their pathophysiology, leading to the development of new diagnostic and screening methods and to innovative therapeutic strategies, is still needed.

The comparison made here has some limitations. One is the lack of appropriate data in regard to relative survival rates of heart failure and stroke. Furthermore, most population-based studies use administrative data from registries and therefore miss detailed clinical information and stage-specific analysis. Retrospective studies with observational design are limited by inaccuracies in the diagnosis and coding of the diseases. The results of the analysis may be influenced by incomplete information concerning prior diagnosis, stage, and severity of the disease and variations in diagnostic accuracy and therapeutic approaches. Competing health risks of patients in clinical studies are not always fully analyzed because the final cause of death is not precisely reported.

\section{Conclusions}

The analysis presented in this paper provides indications that cancer does not necessarily have a poorer prognosis compared to other common causes of death such as heart failure or stroke. Considering the fact that multiple diseases are present in many patients and that this trend is expected to increase in the future due to population ageing, there is an emerged need for a systematic investigation and statistical analysis of long term survival of different diseases within a population, coordinated by interdisciplinary teams. In this way, the role of competing risks will be better evaluated, which is important in order to better understand individual prognostic factors in multimorbid patients, prioritize the treatment of the prognostically leading disease and optimize therapeutic outcome.

Additional file 1: Characteristics and results of the studies investigating 5-year survival of cancer, heart failure and stroke. N/A: Not applicable, m: men, w: women.

\section{Author details}

${ }^{1}$ Department of Radiooncology and Radiation Therapy, University of Heidelberg, Im Neuenheimer Feld 400, 69120, Heidelberg, Germany. ${ }^{2}$ Department of Radiation Therapy, German Cancer Research Center, Im Neuenheimer Feld 280, 69120, Heidelberg, Germany. ${ }^{3}$ Department of Internal Medicine III, University of Heidelberg, Im Neuenheimer Feld 410, 69120, Heidelberg, Germany.

\section{Authors' contributions}

VA, CT and MB made substantial contribution to the conception and design of the study, data analysis, and interpretation, drafted the manuscript, and gave approval of the final version. STP, PM, JT, KL, HAK, and JD were involved in critically revising the manuscript for important intellectual content and gave approval of the final version.

\section{Competing interests}

The authors declare that they have no competing interests.

Received: 2 March 2010 Accepted: 22 March 2010

Published: 22 March 2010

\section{References}

1. Yancik R: Population aging and cancer: a cross-national concern. Cancer J 2005, 11:437-41.

2. Ferlay J, Autier $P$, Boniol M, Heanue M, Colombet M, Boyle P: Estimates of the cancer incidence and mortality in Europe in 2006. Ann Oncol 2007, 18:581-92.

3. Kamangar F, Dores GM, Anderson WF: Pattern of cancer incidence, mortality, and prevalence across five continents: defining priorities to reduce cancer disparities in different geographic regions of the world. Clin Oncol 2006, 24:2137-50.

4. Hortobagyi GN, de la Garza Salazar J, Pritchard K, Amadori D, Haidinger R, Hudis CA, Khaled H, Liu MC, Martin M, Namer M, O'Shaughnessy JA, Shen ZZ, Albain KS, ABREAST Investigators: The global breast cancer burden: variations in epidemiology and survival. Clin Breast Cancer 2005, 6:391-401.

5. Crawford ED: Understanding the epidemiology, natural history, and key pathways involved in prostate cancer. Urology 2009, 73(Suppl 5):4-10.

6. Global cancer facts and figures 2007. [http://www.cancer.org/downloads/ STT/Global_Cancer_Facts_and_Figures_2007_rev.pdf].

7. Weitz J, Koch M, Debus J, Höhler T, Galle PR, Büchler MW: Colorectal cancer. Lancet 2005, 365:153-65.

8. Heart disease and stroke statistics-2007. [http://www.americanheart.org/]

9. Hunt SA, Abraham WT, Chin MH, Feldman AM, Francis GS, Ganiats TG, Jessup M, Konstam MA, Mancini DM, Michl K, Oates JA, Rahko PS, Silver MA, Stevenson LW, Yancy CW: 2009 focused update incorporated into the ACC/AHA 2005 guidelines for the diagnosis and management of heart failure in adults: a report of the American College of Cardiology Foundation/American Heart Association Task Force on practice guidelines: developed in collaboration with the International Society for Heart and Lung Transplantation. Circulation 2009, 119:391-479.

10. Lloyd-Jones D, Adams RJ, Brown TM, Carnethon M, Dai S, De SimoneG, Ferguson TB, Ford E, Furie K, Gillespie C, Go A, Greenlund K, Haase N, Hailpern S, Ho PM, Howard V, Kissela B, Kittner S, Lackland D, Lisabeth L, Marelli A, McDermott MM, Meigs J, Mozaffarian D, Mussolino M, Nichol G, Roger V, Rosamond W, Sacco R, Sorlie P, Stafford R, Thom T, WasserthielSmoller S, Wong ND, Wylie-Rosett J, on behalf of the American Heart Association Statistics Committee and Stroke Statistics Subcommittee: Heart 
disease and stroke statistics-2010 update. A report from the American Heart Association. Circulation 2010, 121:46-215.

11. Koelling TM, Chen RS, Lubwama RN, L'Italien GJ, Eagle KA: The expanding national burden of heart failure in the United States: the influence of heart failure in women. Am Heart J 2004, 147:74-8.

12. Warlow C: Epidemiology of stroke. Lancet 1998, 352(Suppl 3):1-4.

13. Warlow C, Sudlow C, Dennis M, Wardlaw J, Sandercock P: Stroke. Lancet 2003, 362:1211-24.

14. Wolfe CD, Giroud M, Kolominsky-Rabas P, Dundas R, Lemesle M, Heuschmann P, Rudd A, for the European Registries of Stroke (EROS) Collaboration: Variations in stroke incidence and survival in 3 areas of Europe. Stroke 2000, 31:2074-2079.

15. Brønnum-Hansen H, Davidsen M, Thorvaldsen P, Danish MONICA Study Group: Long-term survival and causes of death after stroke. Stroke 2001, 32:2131-6.

16. De Jong G, van Raak L, Kessels F, Lodder J: Stroke subtype and mortality: a follow-up study in 998 patients with first cerebral infarct. J Clin Epidemiol 2003, 56:262-8.

17. Hankey GJ: Long-term outcome after ischaemic stroke/transient ischaemic attack. Cerebrovasc Dis 2003, 16(Suppl 1):14-19.

18. Berrino F, Sant M, Verdecchia A, Capocaccia R, Hakulinen T: Survival of cancer patients in Europe: the EUROCARE Study Lyon. IARC Scientific Publications No. 1321995.

19. Berrino F, Capocaccia R, Estève J, Gatta G, Hakulinen T, Micheli A, Sant M, Verdecchia A: Survival of cancer patients in Europe: the EUROCARE-2 study Lyon. IARC Scientific Publications No. 1511999.

20. Sant M, Aareleid T, Berrino F, Bielska Lasota M, Carli PM, Faivre J, Grosclaude P, Hédelin G, Matsuda T, Møller H, Möller T, Verdecchia A, Capocaccia R, Gatta G, Micheli A, Santaquilani M, Roazzi P, Lisi D, EUROCARE Working Group: EUROCARE-3: survival of cancer patients diagnosed 1990-94-results and commentary. Ann Oncol 2003, 14(Suppl 5):61-118.

21. Sant M, Allemani C, Santaquilani M, Knijn A, Marchesi F, Capocaccia R, EUROCARE Working Group: EUROCARE-4. Survival of cancer patients diagnosed in 1995-1999. Results and commentary. Eur J Cancer 2009, 45:931-91

22. Gondos A, Holleczek B, Arndt V, Stegmaier C, Ziegler H, Brenner H: Trends in population-based cancer survival in Germany: to what extent does progress reach older patients? Ann Oncol 2007, 18:1253-9.

23. Gondos A, Arndt V, Holleczek B, Stegmaier C, Ziegler H, Brenner H: Cancer survival in Germany and the United States at the beginning of the 21st century: an up-to-date comparison by period analysis. Int J Cancer 2007, 121:395-400

24. Grivaux M, Zureik M, Marsal L, Asselain B, Peureux M, Chavaillon JM, Prud'homme A, Carbonnelle M, Goarant E, Maury B, Bedossa A, Blanchon F: Five year survival for lung cancer patients managed in general hospitals. Rev Mal Respir 2009, 26:37-44.

25. Coleman MP, Quaresma M, Berrino F, Lutz JM, De Angelis R, Capocaccia R, Baili P, Rachet B, Gatta G, Hakulinen T, Micheli A, Sant M, Weir HK Elwood JM, Tsukuma H, Koifman S, E Silva GA, Francisci S, Santaquilani M, Verdecchia A, Storm HH, Young JL, CONCORD Working Group: Cancer survival in five continents: a worldwide population-based study (CONCORD). Lancet Oncol 2008, 9:730-56.

26. Meliker JR, Goovaerts P, Jacquez GM, Avruskin GA, Copeland G: Breast and prostate cancer survival in Michigan: can geographic analyses assist in understanding racial disparities? Cancer 2009, 115:2212-21.

27. SEER cancer statistics review 1975-2005. [http://seer.cancer.gov/csr/ 1975_2005/

28. Chia SE, Tan CS, Lim GH, Sim X, Pawitan Y, Reilly M, Mohamed Ali S, Lau W, Chia KS: Incidence, mortality and survival patterns of prostate cancer among residents in Singapore from 1968 to 2002. BMC Cancer 2008, 8:368

29. Birgisson H, Talbäck M, Gunnarsson U, Påhlman L, Glimelius B: Improved survival in cancer of the colon and rectum in Sweden. Eur J Surg Oncol 2005, 31:845-53

30. Jhund PS, Macintyre K, Simpson CR, Lewsey JD, Stewart S, Redpath A, Chalmers JW, Capewell S, McMurray JJ: Long-term trends in first hospitalization for heart failure and subsequent survival between 1986 and 2003: a population study of 5.1 million people. Circulation 2009, 119:515-23.
31. Blackledge HM, Tomlinson J, Squire IB: Prognosis for patients newly admitted to hospital with heart failure: survival trends in 12220 index admissions in Leicestershire 1993-2001. Heart 2003, 89:615-20.

32. Mahjoub H, Rusinaru D, Soulière V, Durier C, Peltier M, Tribouilloy C: Longterm survival in patients older than 80 years hospitalised for heart failure. A 5-year prospective study. Eur J Heart Fail 2008, 10:78-84.

33. Tribouilloy C, Rusinaru D, Mahjoub H, Soulière V, Lévy F, Peltier M, Slama M, Massy Z: Prognosis of heart failure with preserved ejection fraction: a 5 year prospective population-based study. Eur Heart J 2008, 29:339-47.

34. Owan TE, Hodge DO, Herges RM, Jacobsen SJ, Roger VL, Redfield MM: Trends in prevalence and outcome of heart failure with preserved ejection fraction. N Engl J Med 2006, 355:251-9.

35. Bravata DM, Ho SY, Brass LM, Concato J, Scinto J, Meehan TP: Long-term mortality in cerebrovascular disease. Stroke 2003, 34:699-704.

36. Kim HC, Choi DP, Ahn SV, Nam CM, Suh I: Six-year survival and causes of death among stroke patients in Korea. Neuroepidemiology 2009, 32:94-100.

37. Reggiani M, Società Inter-Regionale Piemonte e Valle d'Aosta per le Cerebrovasculopatie Group: Five-year survival after first-ever ischaemic stroke is worse in total anterior circulation infarcts: The SINPAC Cohort. Cerebrovasc Dis 2009, 27:29-36.

38. Vernino S, Brown RD Jr, Sejvar JJ, Sicks JD, Petty GW, O'Fallon WM: Causespecific mortality after first cerebral infarction: a population-based study. Stroke 2003, 34:1828-32.

39. Cheung CM, Tsoi TH, Hon SF, Au-Yeung M, Shiu KL, Lee CN, Huang CY: Outcomes after first-ever stroke. Hong Kong Med J 2007, 13:95-9.

40. Hardie K, Hankey GJ, Jamrozik K, Broadhurst RJ, Anderson C: Ten-year survival after first-ever stroke in the Perth Community Stroke Study. Stroke 2003, 34:1842-6.

41. Hardie K, Jamrozik K, Hankey GJ, Broadhurst RJ, Anderson C: Trends in fiveyear survival and risk of recurrent stroke after first-ever stroke in the Perth Community Stroke Study. Cerebrovasc Dis 2005, 19:179-85.

42. Hakulinen T: Cancer survival corrected for heterogeneity in patient withdrawal. Biometrics 1982, 38:933-42.

43. Dickman PW, Sloggett A, Hills M, Hakulinen T: Regression models for relative survival. Stat Med 2004, 23:51-64.

44. Stewart S, MacIntyre K, Hole DJ, Capewell S, McMurray JJ: More 'malignant' than cancer? Five-year survival following a first admission for heart failure. Eur J Heart Fail 2001, 3:315-22.

45. Chiang CL: Competing risks in mortality analysis. Annu Rev Publ Health 1991, 12:281-307.

46. Rothenberg RB: Competing mortality and progress against cancer. Epidemiology 1994, 5:197-203.

47. Llorca J, Delgado-Rodríguez M: Competing risks analysis using Markov chains: impact of cerebrovascular and ischaemic heart disease in cancer mortality. Int J Epidemiol 2001, 30:99-101.

\section{Pre-publication history}

The pre-publication history for this paper can be accessed here: http://www. biomedcentral.com/1471-2407/10/105/prepub

doi:10.1186/1471-2407-10-105

Cite this article as: Askoxylakis et al: Long-term survival of cancer patients compared to heart failure and stroke: A systematic review. $B M C$ Cancer 2010 10:105.

\section{Submit your next manuscript to BioMed Central and take full advantage of:}

- Convenient online submission

- Thorough peer review

- No space constraints or color figure charges

- Immediate publication on acceptance

- Inclusion in PubMed, CAS, Scopus and Google Scholar

- Research which is freely available for redistribution 